\title{
Rachel Lauthelier, Quand le récit de l'aventure supplante la relation de voyage: le voyage en Perse au XVIII siècle
}

\section{Franco Piva}

\section{(2) OpenEdition \\ 1 Journals}

\section{Edizione digitale}

URL: http://journals.openedition.org/studifrancesi/30251

DOI: $10.4000 /$ studifrancesi.30251

ISSN: 2421-5856

\section{Editore}

Rosenberg \& Sellier

\section{Edizione cartacea}

Data di pubblicazione: 1 avril 2006

Paginazione: 152

ISSN: 0039-2944

\section{Notizia bibliografica digitale}

Franco Piva, «Rachel Lauthelier, Quand le récit de l'aventure supplante la relation de voyage: le voyage en Perse au XVIII' siècle», Studi Francesi [Online], 148 (XLX | I) | 2006, online dal 30 novembre 2015, consultato il 19 avril 2021. URL: http://journals.openedition.org/studifrancesi/30251 ; DOI: https:// doi.org/10.4000/studifrancesi.30251

Questo documento è stato generato automaticamente il 19 avril 2021.

\section{cc) $(9)$}

Studi Francesi è distribuita con Licenza Creative Commons Attribuzione - Non commerciale - Non opere derivate 4.0 Internazionale. 


\title{
Rachel Lauthelier, Quand le récit de l'aventure supplante la relation de voyage: le voyage en Perse au XVIII siècle
}

\author{
Franco Piva
}

\section{NOTIZIA}

RACHEL LAUTHELIER, Quand le récit de l'aventure supplante la relation de voyage: le voyage en Perse au XVIII' siècle, «Revue d'Histoire littéraire de la France», 2004, n. 4, pp. 871-886.

È noto da tempo il ruolo che le relazioni di viaggio ebbero all'interno di quella che Paul Hazard ha chiamato «la crise de la conscience européenne», così come è nota l'importanza che in questo contesto svolsero le relazioni che dei loro viaggi in Persia, e più in generale in Medio Oriente, pubblicarono negli ultimi anni dei Seicento o nei primi del Settecento, viaggiatori come Jean Thevenot, Jean Chardin, o Jean-Baptiste Tavernier, per non citare che i più noti. Gli storici delle idee a questi testi hanno da tempo dato l'importanza che essi indubbiamente meritavano. Minore attenzione questi stessi testi hanno suscitato presso i letterati, anche se negli ultimi tempi non sono mancati coloro che alle relazioni di viaggio hanno iniziato a guardare come a testi con una loro dimensione e valenza letteraria, a testi soprattutto che, se letti con attenzione, dicono del loro autore cose altrettanto interessanti di quelle che l'autore scrive sul paese da lui visitato. Ci si è cioè resi conto che queste relazioni sono spesso, e sempre più spesso a mano a mano che ci si inoltra nel Settecento, il luogo in cui l'autore della relazione di viaggio si trasforma nel protagonista di una avventura del tutto personale, di modo che la relazione diventa non di rado «le récit d'une vie», nel quale il fantasmatico si mescola talvolta con la realtà, il vero con l'inventato, il banale con lo straordinario e che obbedisce, comunque, a regole che sono psicologiche e letterarie insieme. È su questa dimensione che si muove l'interessante articolo di Rachel 
Lauthelier che, oltretutto, in appendice offre un ricco elenco di relazioni di viaggi in Persia tra Sei e Settecento che potrà facilitare non solo il reperimento, sovente non agevole, di queste relazioni, ma anche lo studio delle problematiche legate alla loro scrittura ed alla loro letterarietà. 